\title{
0428 HOW INFORMED ARE THE PARENTS ABOUT THE BURDEN OF INJURIES?
}

A Mujkic*, M Miskulin, V Crnica, L Kovacic Correspondence: Department for Social Medicine, School of Medicine, Andrija Stampar School of Public Health, University of Zagreb, Rockefellerova 4, Zagreb 10 000, Croatia

10.1136/ip.2010.029215.428

Objective Determining the knowledge and attitudes towards injury prevention/safety promotion (IPSP) for pre-school children among Croatian parents of newborn babies.

Participants 351 parents (285 mothers, 66 fathers).

Methods Anonymous self-administered questionnaire containing demographic items and items on knowledge and attitudes regarding IPSP for pre-school children.

Main Outcome Measures Knowledge and attitudes towards IPSP for pre-school children.

Results The answers the parents gave varied greatly for the 40 questions asked. For example: almost all parents showed correct attitudes and knowledge regarding leaving an infant unsupervised in water $(99.3 \%$ mothers, $100 \%$ fathers answered correctly), having pre-school child sitting at the front seat if held by an adult $(99.3 \%$ mothers, $100 \%$ fathers answered correctly) and playground safety $(98.2 \%$ mothers, $100 \%$ fathers answered correctly). An adequate number $(73.9 \%$ mothers, $76,9 \%$ fathers) chose the correct answer on the question related to the storage of chemicals and a similar number $(77.5 \%$ mothers, $65.6 \%$ fathers) said they indeed did store them in the proper manner. It was shocking to see how low they scored on some very important questions: $35.9 \%$ mothers and $23.1 \%$ fathers recognise child-walkers as dangerous and only 12.7 fathers and $20.0 \%$ mothers knew that the safest position for sleeping for an infant is on the back.

Conclusions Parents play a crucial role in injury prevention/ safety promotion as models for their children, their educators and persons in the position to intervene within environment making it safer. Therein lays the importance of their sufficient knowledge and positive attitudes. Our results show a need for further public health education of the parents. 